\title{
Active Hexose Correlated Compound (AHCC) Alleviates Gemcitabine-Induced Hematological Toxicity in Non-Tumor-Bearing Mice*
}

\author{
Daisuke Nakamoto, Kota Shigama, Hiroshi Nishioka", Hajime Fujii
}

Amino Up Chemical Co., Ltd., Sapporo, Japan.

Email: \#nishioka@aminoup.jp

Received May $16^{\text {th }}$, 2012; revised June $17^{\text {th }}$, 2012; accepted July $16^{\text {th }}, 2012$

\begin{abstract}
Active hexose correlated compound (AHCC) is known as a dietary supplement derived from an extract of a basidiomycete mushroom. The present study was conducted to evaluate the role of AHCC in alleviating the side effects, particularly hematological toxicity, in non-tumor-bearing mice receiving monotherapy with gemcitabine (GEM). The results from the GEM treatment groups with and without AHCC administration were compared to control group that received vehicle alone. The GEM alone treatment reduced peripheral leukocytes and hemoglobin, and bone marrow cell viability in spite of no influence on body weight, food consumption, and renal and hepatic parameters. Supplementation with AHCC significantly alleviated these side effects. The colony forming assay of bone marrow cells revealed that AHCC improved reduction of colony forming unit-granulocyte macrophage (CFU-GM) and burst forming unit-erythroid (BFU-E) related to GEM administration. However, when mRNA expression of granulocyte-macrophage colony-stimulating factor (GM-CSF) and erythropoietin (EPO) was examined using a quantitative reverse transcription polymerase chain reaction (RT-PCR), AHCC showed no effect for the mRNA levels of their hematopoietic growth factors. These results support the concept that AHCC can be beneficial for cancer patients with GEM treatment through alleviating the hematotoxicity.
\end{abstract}

Keywords: Anticancer Drug; Bone Marrow Suppression; Colony Formation; Hemoglobin; Mushroom Extract; White Blood Cells

\section{Introduction}

Gemcitabine (2',2'-difluoro-2'-deoxycytidine, GEM), a pyrimidine based nucleoside analog, [1] is metabolized to gemcitabine diphosphate and triphosphate inside the cell by nucleoside kinases [2]. Gemcitabine diphosphate is a potent inhibitor of ribonucleotide reductase, which is associated with deoxyribonucleotide pools [3]. A reducetion of deoxyribonucleotide concentration leads to the inhibition of DNA synthesis. Gemcitabine triphosphate competes with deoxycytidine triphosphate (dCTP) in binding to replicating DNA polymerases and then is incorporated into DNA to prevent further elongation of the replicating strand, resulting from increase in the ratio of cellular concentrations of gemcitabine triphosphate to dCTP [4]. Thus, the major mechanism of action of GEM is the direct or indirect inhibition of DNA synthesis.

In cancer therapy, GEM is commonly used as a component of adjuvant chemotherapy for advanced pancre-

${ }^{*}$ No competing financial interests exist.

${ }^{\#}$ Corresponding author. atic cancer [5]. Additionally GEM is also used for the treatment of various other carcinomas such as non-small cell lung cancer [6], ovarian cancer [7], breast cancer [8], and biliary tract cancer [9]. The limited toxicity associated with GEM therapy compared to other cytotoxic anticancer drugs is one of the major reasons for the widespread use in chemotherapy. Although hematological toxicity and flu-like symptoms caused by GEM are the most common side effect, they are mild and shortlived [10]. However, these toxicities related to GEM can lower the quality of life in cancer patients and often trigger reductions in the dosage, frequency and duration of chemotherapy, ultimately decreasing potential for optimal therapeutic outcomes.

An approach to relieve the side effects of anticancer drugs including GEM leads to the use of complementary and alternative medicine (CAM) that has attracted great attention. Many cancer patients are currently using CAM in order to reduce the side effects and obtain additional chemotherapeutic effects through boosting the immune system [11]. In Japan, 44.6 percent of cancer patients 
reported using CAM with the most frequently used treatment being dietary supplements of mushrooms such as agaricus (Agaricus blazei Murill) and active hexose correlated compound (AHCC) [12].

AHCC is a mixture of polysaccharides, amino acids, lipids and minerals derived from mycelial culture of the basidiomycete, Lentinula edodes. The predominant component of AHCC is oligosaccharides, which contain $\alpha-1,4$ glucans and partially acetylated $\alpha-1,4$ glucans with a molecular weight of around 5000 Daltons. AHCC has been shown to increase the number and function of dendritic cells in healthy adult humans [13] and enhance both the activation and proliferation of $\mathrm{CD}^{+}$and $\mathrm{CD}^{+} \mathrm{T}$ cells in tumor-bearing mice [14]. AHCC also strengthened the chemotherapeutic effects of UFT (tegafur and uracil in a 4:1 molar concentration) for mammary adenocarcinoma SST-2 cells in rats [15] and cisplatin for Colon-26 tumor cells in mice [16]. Furthermore, two human clinical studies in liver cancer patients showed a significant increase in survival rate among those taking AHCC. $[17,18]$ Several studies have explored the alleviating effects of AHCC for chemotherapy-related side effects. In cisplatin-treated tumor-bearing mice, AHCC improved food consumption, renal damage and myelosuppression [16]. The role of AHCC in attenuating various side effects was also explored in non-tumor-bearing mice receiving monotherapy with paclitaxel, or multidrug chemotherapy including cisplatin plus paclitaxel, cisplatin plus 5-fluorouracil, 5-fluorouracil plus irinotecan, cyclophosphamide plus doxorubicin, and 6-mercaptopurine plus methotrexate $[19,20]$. In newborn rats, the AHCC-treated group was protected from cytosine arabinoside-caused hair loss [20].

We investigated the influence of AHCC on some of the side effects associated with GEM as an initial study in preparation for a human clinical trail. Non-tumorbearing mice, but not tumor-bearing mice, were chosen so that the intrinsic alterations related to the anticancer agent could be assessed independent of oncological variables. In the present study, we focused on GEM-induced hematotoxicity including bone marrow suppression, which is a dose-limiting toxicity.

\section{Materials and Methods}

\subsection{Reagents}

Active hexose correlated compound (AHCC; Amino Up Chemical Co., Ltd., Sapporo, Japan) was produced from the mycelia culture of Lentinula edodes in a manufacturing process according to Good Manufacturing Practice (GMP) standards for dietary supplements, and ISO9001: 2008 and ISO22000: 2005 criteria [16]. After pre-cultivation in flasks, the basidiomycete was cultured in 15-ton large tanks for 45 days, and then AHCC was obtained through filtration, sterilization, concentration and freezedrying. Gemcitabine (GEM) is a commercially available anticancer drug as Gemzar Injection (Eli Lilly Japan K. K., Kobe, Japan), and the drug was obtained from JUNSEI CHEMICAL CO., LTD. (Tokyo, Japan).

\subsection{Animals}

Specific pathogen-free male ddY mice were purchased from Japan SLC, Inc. (Hamamatsu, Japan) and studied at six weeks of age. Animals were maintained in a temperature- and humidity-controlled room at $23^{\circ} \mathrm{C} \pm 1{ }^{\circ} \mathrm{C}$ and $55 \%-60 \%$, respectively, under a 12-hour light-dark cycle (lights on 08:00 to 20:00), fed a standard pelleted rodent chow (CE-2; CLEA Japan Inc., Tokyo, Japan), and given water ad libitum. Mice were divided into three groups: control (untreated), GEM alone, and GEM plus AHCC. Each group consisted of ten mice.

\subsection{Treatments}

The GEM solution was injected intraperitoneally at a dose of $400 \mathrm{mg} / \mathrm{kg}\left(1200 \mathrm{mg} / \mathrm{m}^{2}\right)$ once a week for three weeks (days 7, 14 and 21). The treatment was similar to the regimen actually used in clinical practice (1000 $\mathrm{mg} / \mathrm{m}^{2}$ of weekly drip infusion three times followed by one week cessation of the drug). AHCC was prepared as a solution at a dosage of $1 \mathrm{~g} / \mathrm{kg}$ and administered daily by gavage to mice seven days before the first injection of GEM and throughout the experiment (day 1 to day 28). The control group received a vehicle (saline) instead of GEM and AHCC. All animals were killed under anesthesia, and blood, bone marrow (BM) cells, spleen and kidney were harvested at day 28.

Since the effect of AHCC was assessed at a dosage range from $100 \mathrm{mg} / \mathrm{kg}$ to $1 \mathrm{~g} / \mathrm{kg}$ in previous studies, [14-16,19,20] a dose of $1 \mathrm{~g} / \mathrm{kg}$ of AHCC was chosen in the current study. The experimental protocol was approved by the Animal Care Committee of Amino Up Chemical Co., Ltd.

\subsection{Evaluation of Parameters}

The following parameters were assessed: body weight, food consumption, liver function (serum aspartate aminotransferase; AST), kidney function (blood nitrogen urea; BUN), hematological toxicities (peripheral total white blood cell count and hemoglobin content), and myelosuppression. Body weight and food consumption were measured twice a week. Serum AST and BUN were assessed using Transaminase CII-test WAKO and Urea Nitrogen B-test WAKO assay kits (Wako Pure Chemical Industries Limited, Osaka, Japan), respectively. Cardiac blood samples were diluted to 1:10 with Turk solution (Wako Pure Chemical Industries Limited) to determine 
the number of total white blood cells in accordance with the Nageotte chamber counting procedure, [21] and hemoglobin content in blood was measured using a Hemoglobin B-test kit (Wako Pure Chemical Industries Limited). Myelosuppression was determined by measuring BM cell viability and by evaluating the responses to colony forming unit granulocyte-macrophage (CFU-GM) and burst forming unit erythroid (BFU-E).

$\mathrm{BM}$ cell viability was determined by collecting BM cells from the femur, which were first suspended in $0.83 \% \mathrm{NH}_{4} \mathrm{Cl}$ solution and incubated at $37^{\circ} \mathrm{C}$ for ten minutes to hemolyze red blood cells. After centrifugation, the cells were prepared at a concentration of $1 \times 10^{7}$ cells $/ \mathrm{mL}$ in DMEM supplemented with $10 \%$ FBS. A $100-\mu \mathrm{L}$ aliquot of the suspension was cultured in a 96-well plate for three days, and the viability (percent of control group) of BM cells was estimated by a MTT assay. The detection of CFU-GM and BFU-E was performed using a colony forming cell assay kit, MethoCult (StemCell Technologies, Vancouver, Canada). Briefly, BM cells were suspended in Iscove's MDM (IMDM) with $2 \%$ FBS and the suspension $\left(2 \times 10^{5}\right.$ cells $\left./ \mathrm{mL}\right)$ was mixed with methylcellulose medium containing rmSCF, rmIL-3 and rhIL-6 (MethoCult 3534) at a 1:9 ratio. The prepared BM cells $\left(2 \times 10^{4}\right.$ cells $\left./ \mathrm{mL}\right)$ were plated onto a $35-\mathrm{mm}$ dish and incubated at $37^{\circ} \mathrm{C}$ for eight days to form CFU-GM colony. For a mature BFU-E assay, after IMDM with $2 \%$ FBS was added at a 1:9 ratio to methylcellulose medium containing rhEpo (MethoCult 3334), BM cells $\left(2 \times 10^{6}\right.$ cells $\left./ \mathrm{mL}\right)$ in IMDM with $2 \%$ FBS were mixed with the diluted methylcellulose medium at a 1:9 ratio. The prepared $\mathrm{BM}$ cells $\left(2 \times 10^{5}\right.$ cells $\left./ \mathrm{mL}\right)$ were plated onto a $35-\mathrm{mm}$ dish and incubated at $37^{\circ} \mathrm{C}$ for four days. Following the individual incubation time, CFUGM and mature BFU-E colonies were counted under a microscope to quantify murine hematopoietic progenitor cells.

\subsection{Reverse Transcription Polymerase Chain Reaction}

Expression of granulocyte-macrophage colony-stimulating factor (GM-CSF), erythropoietin (EPO) and beta-2microglobulin (B2M) mRNA was determined using a quantitative reverse transcription polymerase chain reaction (RT-PCR). Total RNA was extracted from $100 \mathrm{mg}$ of spleen and kidney with TRIzol reagent (Invitrogen Corp., Carlsbad, CA, USA) according to the manufacturer's protocol. First-strand cDNA was obtained by incubation of $1.6 \mu \mathrm{g}$ of total RNA with PrimeScript 2 1st strand cDNA Synthesis kit (Takara Bio Inc., Otsu, Japan), and the RT product was then diluted to $10 \mu \mathrm{g} / \mu \mathrm{L}$ and subjected to PCR using TaKaRa ExTaq (Takara Bio Inc.). Forty cycles of amplification were carried out for GM-
CSF mRNA, and EPO mRNA and B2M mRNA were 37 and 22 cycles, respectively. The condition of each cycle was denaturing at $94^{\circ} \mathrm{C}$ for 30 seconds, annealing at $59^{\circ} \mathrm{C}$ (GM-CSF and $\mathrm{B} 2 \mathrm{M}$ ) and $65^{\circ} \mathrm{C}$ (EPO) for 45 seconds, and extension at $72^{\circ} \mathrm{C}$ for 30 seconds. The primers are described as follows; GM-CSF:

5'-GGCCTTGGAAGCATGTAGAG-3' (sense) and 5'ATGAAATCCGCATAGGTGGT-3' (antisense); EPO: 5'-CCACCCTGCTGCTTTTACTC-3' (sense) and 5'GGCCTTGCCAAACTTCTATG-3' (antisense); B2M: 5'-TAGCTGTGCTCGCGCTACT-3' (sense) and 5'AGTGGGGGTGAATTCAGTGT-3' (antisense). The gene bands in each sample were normalized to the corresponding B2M band using Alpha Innotech red ${ }^{\mathrm{TM}}$ (Alpha Innotech Corp., San Leandro, CA, USA).

\subsection{Statistical Analysis}

Experimental data are shown as mean \pm standard error of the mean (SEM). Data were analyzed by one-way analysis of variance (ANOVA). Fisher's Protected Least Significance Difference (PLSD) was used as a post hoc test, and values of $p$ less than 0.05 were determined to be statistically significant.

\section{Results}

\subsection{Peripheral Hematological Toxicity}

To determine whether AHCC is capable of protecting against GEM-related hematotoxicity, peripheral total white blood cell count and hemoglobin content in blood were monitored. As shown in Figures 1(a) and (b), GEM treatment was significantly associated with reductions of leukocyte count and hemoglobin content $(p<0.01)$, and supplementation with AHCC completely ameliorated both hematological toxicities $(p<0.01)$. The values of white blood cells $\left(\times 10^{6}\right.$ cells $\left./ \mathrm{mL}\right)$ in the control, GEM, and GEM + AHCC groups were $3.05 \pm 0.13,2.01 \pm 0.12$, and $3.03 \pm 0.13$, respectively. Hemoglobin content (g/dL) was $14.4 \pm 0.2$ (control), $13.1 \pm 0.3$ (GEM), and $14.7 \pm$ 0.3 (GEM plus AHCC).

\subsection{Bone Marrow (BM) Suppression}

To elucidate the alleviating effect of AHCC for GEMinduced myelosuppression, BM damage was assessed by BM cell viability and the colony forming ability of hematopoietic progenitor cells. The viability of BM cells isolated from GEM-treated mice was lower than that of the control group ( $p<0.01$; Figure 2), and AHCC administration significantly reversed the decline although it did not achieve complete recovery ( $p<0.01$ vs GEM, control). Treatment with GEM alone significantly lowered 


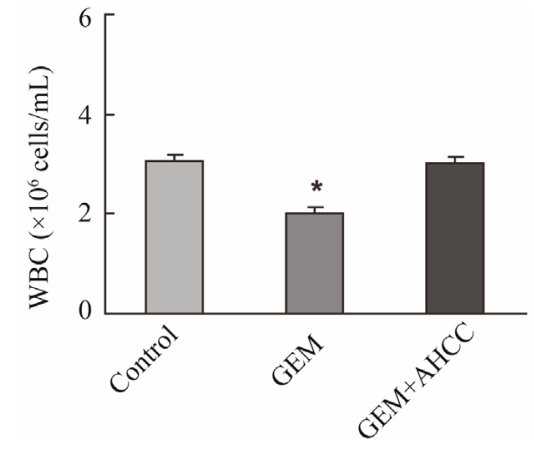

(a)

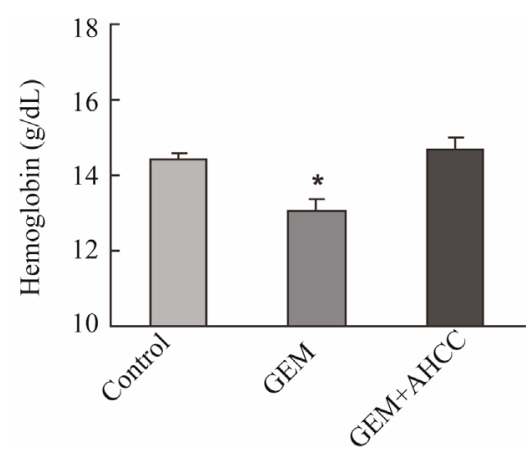

(b)

Figure 1. Alleviating effect of AHCC for GEM-related hemaotopoietic toxicity. Blood was collected from mice on the final day of the experiment (day 28), and GEM-induced hematotoxity was evaluated using two parameters, which were peripheral total white blood cell count (a) and hemoglobin content in blood (b). Blood samples were diluted to 1:10 with Turk solution to determine the number of total white blood cells based on the Nageotte chamber counting procedure. Hemoglobin content was analyzed by a Hemoglobin B-test WAKO assay kit. The values show the mean \pm SEM. ${ }^{*} \boldsymbol{p}<0.01$ vs control, GEM plus AHCC.

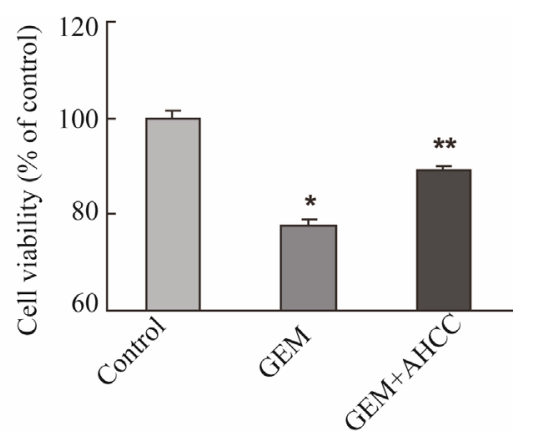

Figure 2. Ameliorative effect of AHCC on bone marrow (BM) cell viability. On day 28 , BM cells were isolated from femurs of mice with or without GEM injection, and the hemolyzed BM cells $\left(1 \times 10^{7}\right.$ cells/mL) were cultured in a 96-well plate for 3 days. The viability (\% of control group) of BM cells was estimated by a MTT assay. The values (\% of control; mean \pm SEM) in the control, GEM alone, and GEM plus AHCC groups were $100.0 \pm 1.5,77.5 \pm 1.3$ and $89.0 \pm 0.9$, respectively. ${ }^{*} p<0.01$ vs control, GEM plus AHCC, ${ }^{* *} p<0.01$ vs control. both CFU-GM and BFU-E forming abilities $(p<0.01$; Table 1), while the lowering was entirely recovered to control level by AHCC administration.

\subsection{Expression of GM-CSF and EPO mRNA}

Expression of GM-CSF and EPO mRNA in spleen and kidney, respectively, was compared among control, GEM alone, and GEM plus AHCC groups. The expression level was calculated as a percent of control after each band of GM-CSF and EPO was normalized to the corresponding B2M band (Table 2). The mRNA levels of both GM-CSF and EPO in the GEM alone group were significantly higher than those of the control and the GEM plus AHCC groups $(p<0.05)$. In contrast, the expression levels in AHCC-treated mice were identical to control.

\subsection{Other Toxicities}

No changes in body weight, food consumption, and liver and renal functions were noted at the completion of the study. The average of body weight (g) was $35.4 \pm 1.0$, $36.3 \pm 0.7$, and $35.9 \pm 0.6$ in the control, GEM alone, and GEM+AHCC groups, respectively. Serum AST and BUN values were also normal and did not change during the course of the study (data not shown), which was consistent with previous data [10].

\section{Discussion}

Gemcitabine (GEM) has shown activity in a variety of solid tumors [22]. The drug has been approved for the treatment of non-small cell lung cancer, pancreatic can-

Table 1. Colony forming responses of CFU-GM and BFU-E.

\begin{tabular}{ccc}
\hline Group & CFU-GM & BFU-E \\
\hline Control & $88.3 \pm 1.7$ & $119.3 \pm 6.1$ \\
GEM & $64.3 \pm 8.6^{*}$ & $29.0 \pm 0.6^{* *}$ \\
GEM+AHCC & $104.0 \pm 3.0$ & $109.0 \pm 8.1$ \\
\hline
\end{tabular}

All values (colony counts) represent the mean \pm SEM. ${ }^{*} p<0.05$ vs control, $p<0.01$ vs GEM + AHCC, ${ }^{* * * *} p<0.01$ vs control, GEM + AHCC. CFU-GM: colony forming unit-granulocyte macrophage, BFU-E: burst forming uniterythroid.

Table 2. mRNA levels of GM-CSF and EPO.

\begin{tabular}{ccc}
\hline Group & GM-CSF & EPO \\
\hline Control & $100.0 \pm 27.4$ & $100.0 \pm 6.6$ \\
GEM & $323.3 \pm 74.1^{*}$ & $161.9 \pm 19.4^{*}$ \\
GEM+AHCC & $92.9 \pm 20.0$ & $99.6 \pm 3.5$ \\
\hline
\end{tabular}

All values (\% of control) show the mean \pm SEM. ${ }^{*} p<0.05$ vs control, GEM + AHCC. GM-CSF: granulocyte-macrophage colony-stimulating factor, EPO: erythropoietin. 
cer and biliary tract cancer in Japan, and non-small cell lung, pancreatic, ovarian and breast cancers in the United States. Although GEM is generally well tolerated and has a good toxicity profile, myelosuppression is the most common side effect, which can limit dose and thus potentially its therapeutic efficacy. This study was designed to investigate the impact of AHCC in terms of side effects, particularly hematological toxicity attributable to GEM injection, in non-tumor-bearing mice.

The treatment with GEM caused reduction of white blood cell count and hemoglobin content, respectively leading to leukopenia and anemia. Occurrence of leukopenia often induces infectious complications, which may compromise treatment efficacy. Opportunistic infections are a major cause of morbidity and mortality in cancer patients receiving myelotoxic chemotherapy, resulting from invasive fungal infections, particularly invasive aspergillosis, and an increasing spread of Gram-positive pathogens such as methicillin-resistant Staphylococcus aureus and vancomycin-resistant enterococci [23]. In current clinical practice, colony-stimulating factors such as granulocyte colony-stimulating factor (G-CSF) and granulocyte-macrophage colony-stimulating factor (GMCSF) are increasingly used to recover white blood cell counts or increase dose-density [24]. In addition, hemoglobin reduction results in anemia, which is associated with a significant decrease in the quality of life and may limit the applicability and efficacy of anticancer drugs [25]. The treatment with recombinant human erythropoietin (rHu Epo) has been shown to improve anticancer drug-induced anemia in rats [26], and alleviating anemia with rHu Epo in humans has improved the quality of life of cancer patients [27].

Although G-CSF and GM-CSF are generally safe, well tolerated and have favorable outcomes, several reports of serious G-CSF and GM-CSF associated side effects exist, $[28,29]$ including enhanced bone tumor growth by GCSF in mice in an osteoclast-dependent manner [30]. Treatment with rHu EPO also has risks such as the potential to promote cellular proliferation and migration in melanoma and breast cancer cells expressing the Epo receptor [31,32]. AHCC exerted no influence on mRNA levels of GM-CSF and EPO in our study when the mRNA levels were measured. However, given the ameliorating effects of AHCC for GEM-associated BM cell viability, AHCC might be useful to complement the properties of G-CSF and GM-CSF as well as Epo. The beneficial effects of AHCC on hematotoxicities caused by other anticancer drugs, such as cisplatin, paclitaxel, 5-fluorouracil and irinotecan, have been reported $[16,19]$, although the mechanism of action is not yet clear.

AHCC supplementation was significantly associated with an improvement in the levels of colony forming unit granulocyte-macrophage (CFU-GM) and burst forming unit erythroid (BFU-E), which were severely depressed as a result of GEM treatment. AHCC might therefore alleviate chemotherapy-related hematological toxicity through protecting hematopoietic progenitor cells. This result is consistent with other studies demonstrating that Maitake $\beta$-glucans promoted bone marrow cell viability and protected the bone marrow stem cell colony formation unit from doxorubicin-induced hematological toxicity, [33] as well as induced hematopoietic stem cell proliferation and differentiation [34].

Despite the side effects, GEM may be a useful agent for tumor immunotherapy since it possesses significant immunomodulatory activity independent of its cytotoxic effects as shown in murine tumor models [35]. Other agents with potentially harsh side effects, such as cisplatin, have also been to increase the susceptibility of tumor cells to tumor-infiltrating lymphocytes or natural killer cells [36]. Therefore, AHCC may offer promise when used in conjunction with chemotherapy since AHCC may help reduce side effects of drugs like GEM or cisplatin and enable a full chemotherapeutic regimen to be administered. Furthermore, the previous study demonstrated that AHCC enhanced chemotherapeutic effect of cisplatin in tumor-bearing mice [16], suggesting an adjuvant action of AHCC.

The safety of AHCC in cancer patients and healthy volunteers has been previously reported [13,17,18,37]. The current and previous studies suggest that AHCC consumption may be safe in combination with GEM and perhaps other chemotherapy agents that are not metabolized via the CYP450 2D6 pathway [38] and clinical studies are warranted.

The present study was conducted to assess whether AHCC reduces GEM-induced side effects, particularly hematological toxicity that is a dose limiting factor for GEM, in non-tumor-bearing mice. As a consequence, AHCC significantly ameliorated reduction of peripheral total white blood cell count and hemoglobin content, and further resulted in recovering CFU-GM and BFU-E forming abilities. If these results are extended to humans, AHCC might contribute to improved quality of life and well-being of cancer patients undergoing chemotherapy including GEM treatment.

\section{Acknowledgements}

We are deeply grateful to Dr. Robert M. Hackman, University of California-Davis, and Dr. Judith A. Smith, University of Texas, MD Anderson Cancer Center, for their suggestions and editorial comments.

\section{REFERENCES}

[1] L. Hertel, J. S. Kroin, J. W. Misner and J. M. Tustin, 
"Synthesis of 2-Deoxy-2,2-difluoro-D-ribose and 2-Deoxy-2,2-difluoro-D-ribofuranosyl Nucleotides,” The Journal of Organic Chemistry, Vol. 53, 1988, pp. 2406-2409. doi:10.1021/jo00246a002

[2] V. Gandhi, S. Mineishi, P. Huang, Y. Yang, S. Chubb, A. J. Chapman, B. J. Nowak, L. W. Hertel and W. Plunkett, "Difluorodeoxyguanosine: Cytotoxicity, Metabolism, and Actions on DNA Synthesis in Human Leukemia Cells," Seminars in Oncology, Vol. 22, No. 4, 1995, pp. 61-67.

[3] V. Heinemann, Y. Z. Xu, S. Chubb, A. Sen, L. W. Hertel, G. B. Grindey and W. Plunkett, "Inhibition of Ribonucleotide Reduction in CCRF-CEM Cells by 2',2'-Difluorodeoxycytidine," Molecular Pharmacology, Vol. 38, No. 4, 1990, pp. 567-572.

[4] P. Huang, S. Chubb, L. W. Hertel, G. B. Grindey and W. Plunkett, "Action of 2',2'-Difluorodeoxycytidine on DNA Synthesis," Cancer Research, Vol. 51, No. 22, 1991, pp. 6110-6117.

[5] C. J. Campen, T. Dragovich and A. F. Baker, "Management Strategies in Pancreatic Cancer," American Journal of Health-System Pharmacy, Vol. 68, No. 7, 2011, pp. 573-584. doi:10.2146/ajhp100254

[6] G. Bepler, K. E. Sommers, A. Cantor, X. Li, A. Sharma, C. Williams, A. Chiappori, E. Haura, S. Antonia, T. Tanvetyanon, G. Simon, C. Obasaju and L. A. Robinson, "Clinical Efficacy and Predictive Molecular Markers of Neoadjuvant Gemcitabine and Pemetrexed in Resectable Non-Small Cell Lung Cancer," Journal of Thoracic Oncology, Vol. 3, No. 10, 2008, pp. 1112-1118. doi:10.1097/JTO.0b013e3181874936

[7] D. L. Richardson, F. J. Backes, L. G. Seamon, V. Zanagnolo, D. M. O’Malley, D. E. Cohn, J. M. Fowler and L. J. Copeland, "Combination of Gemcitabine, Platinum, and Bevacizumab for the Treatment of Recurrent Ovarian Cancer," Gynecologic Oncology, Vol. 111, No. 3, 2008, pp. 461-466. doi:10.1016/j.ygyno.2008.08.011

[8] S. Moulder, N. Valkov, A. Neuger, J. Choi, J. H. Lee, S. Minton, P. Munster, J. Gump, M. Lacevic, R. Lush and D. Sullivan, "Phase 2 Study of Gemcitabine and Irinotecan in Metastatic Breast Cancer with Correlatives to Determine Topoisomerase I Localization as a Predictor of Response,” Cancer, Vol. 113, No. 10, 2008, pp. 2646-2654. doi:10.1002/cncr.23916

[9] J. W. Valle, H. Wasan, P. Johnson, E. Jones, L. Dixon, R. Swindell, S. Baka, A. Maraveyas, P. Corrie, S. Falk, S. Gollins, F. Lofts, L. Evans, T. Meyer, A. Anthoney, T. Iveson, M. Highley, R. Osborne and J. Bridgewater, "Gemcitabine Alone or in Combination with Cisplatin in Patients with Advanced or Metastatic Cholangiocarcinomas or Other Biliary Tract Tumours: A Multicentre Randomized Phase II Study-The UK ABC-01 Study," British Journal of Cancer, Vol. 101, No. 4, 2009, pp. 621627. doi:10.1038/sj.bjc.6605211

[10] M. Tonato, A. M. Mosconi and C. Martin, "Safety Profile of Gemcitabine,” Anti-Cancer Drugs, Vol. 6, 1995, pp. 27-32. doi:10.1097/00001813-199512006-00005

[11] P. J. Mansky and D. B. Wallerstedt, "Complementary Medicine in Palliative Care and Cancer Symptom Man- agement,” The Cancer Journal, Vol. 12, No. 5, 2006, pp. 425-431. doi:10.1097/00130404-200609000-00011

[12] I. Hyodo, N. Amano, K. Eguchi, M. Narabayashi, J. Imanishi, M. Hirai, T. Nakano and S. Takashima, "Nationwide Survey on Complementary and Alternative Medicine in Cancer Patients in Japan,” Journal of Clinical Oncology, Vol. 23, No. 12, 2005, pp. 2645-2654. doi:10.1200/JCO.2005.04.126

[13] N. Terakawa, Y. Matsui, S. Satoi, H. Yanagimoto, K. Takahashi, T. Yamamoto, J. Yamano, S. Takai, A. H. Kwon and Y. Kamiyama, "Immunological Effect of Active Hexose Correlated Compound (AHCC) in Healthy Volunteers: A Double-Blind, Placebo-Controlled Trial," Nutrition and Cancer, Vol. 60, No. 5, 2008, pp. 643-651. doi:10.1080/01635580801993280

[14] Y. Gao, D. Zhang, B. Sun, H. Fujii, K. Kosuna and Z. Yin, "Active Hexose Correlated Compound Enhances Tumor Surveillance through Regulating both Innate and Adaptive Immune Responses," Cancer Immunology, Immunotherapy, Vol. 55, No. 10, 2005, pp. 1258-1266. doi:10.1007/s00262-005-0111-9

[15] K. Matsushita, Y. Kuramitsu, Y. Ohiro, M. Obata, M. Kobayashi, Y. Q. Li and M. Hosokawa, "Combination Therapy of Active Hexose Correlated Compound Plus UFT Significantly Reduces the Metastasis of Rat Mammary Adenocarcinoma,” Anti-Cancer Drugs, Vol. 9, No. 4, 1998, pp. 343-350. doi:10.1097/00001813-199804000-00008

[16] A. Hirose, E. Sato, H. Fujii, B. Sun, H. Nishioka and O. I. Aruoma, "The Influence of Active Hexose Correlated Compound (AHCC) on Cisplatin-Evoked Chemotherapeutic and Side Effects in Tumor-Bearing Mice," Toxicology and Applied Pharmacology, Vol. 222, No. 2, 2007, pp. 152-158. doi:10.1016/j.taap.2007.03.031

[17] Y. Matsui, J. Uhara, S. Satoi, M. Kaibori, H. Yamada, H. Kitade, A. Imamura, S. Takai, Y. Kawaguchi, A. H. Kwon and Y. Kamiyama, "Improved Prognosis of Postoperative Hapatocellular Carcinoma Patients When Treated with Functional Food: A Prospective Cohort Study," Journal of Hepatology, Vol. 37, No. 1, 2002, pp. 78-86. doi:10.1016/S0168-8278(02)00091-0

[18] S. Cowawintaweewat, S. Manoromana, H. Sriplung, T. Khuhaprema, P. Tongtawe, P. Tapchaisri and W. Chaicumpa, "Prognostic Improvement of Patients with Advanced Liver Cancer after Active Hexose Correlated Compound (AHCC) Treatment,” Asian Pacific Journal of Allergy and Immunology, Vol. 24, No. 1, 2006, pp. 33-45.

[19] K. Shigama, A. Nakaya, K. Wakame, H. Nishioka and H. Fujii, "Alleviating Effect of Active Hexose Correlated Compound (AHCC) for Anticancer Drug-Induced Side Effects in Non-Tumor-Bearing Mice,” Journal of Experimental Therapeutics and Oncology, Vol. 8, No. 1, 2009, pp. 43-51.

[20] B. Sun, K. Wakame, E. Sato, H. Nishioka, O. I. Aruoma and H. Fujii, "The Effect of Active Hexose Correlated Compound in Modulating Cytosine Arabinoside-Induced Hair Loss, and 6-Mercaptopurine- and Methotrexate-Induced Liver Injury in Rodents,” Cancer Epidemiology, 
Vol. 33, No. 3-4, 2009, pp. 293-299.

doi:10.1016/j.canep.2009.07.006

[21] M. Masse, C. Naegelen, N. Pellegrini, J. M. Segier, N. Marpaux and F. Beaujean, "Validation of a Simple Method to Count Vary Low White Cell Concentrations in Filtered Red Cells or Platelets," Transfusion, Vol. 32, No. 6, 1992, pp. 565-571. doi:10.1046/j.1537-2995.1992.32692367203.x

[22] L. Toschi, G. Finocchiaro, S. Bartolini, V. Gioia and F. Cappuzzo, "Role of Gemcitabine in Cancer Therapy," Future Oncology, Vol. 1, No. 1, 2005, pp. 7-17. doi:10.1517/14796694.1.1.7

[23] G. Maschmeyer and A. Haas, "The Epidemiology and Treatment of Infections in Cancer Patients,” International Journal of Antimicrobial Agents, Vol. 31, No. 3, 2008, pp. 193-197. doi:10.1016/j.ijantimicag.2007.06.014

[24] D. C. Dale, "Colony-Stimulating Factors for the Management of Neutropenia in Cancer Patients," Drugs, Vol. 62, 2002, pp. 1-15. doi:10.2165/00003495-200262001-00001

[25] D. Cella, D. Dobrez and J. Glaspy, "Control of CancerRelated Anemia with Erythropoietic Agents: A Review of Evidence for Improved Quality of Life and Clinical Outcomes," Annals of Oncology, Vol. 14, 2003, pp. 511-519. doi:10.1093/annonc/mdg167

[26] T. Matsumoto, K. Endoh, K. Kamisango, K. Akamatsu, K. Koizumi, M. Higuchi, N. Imai, H. Mitsui and T. Kawaguchi, "Effect of Recombinant Human Erythropoietin on Anticancer Drug-Induced Anaemia,” British Journal of Haematology, Vol. 75, No. 4, 1990, pp. 463-468. doi:10.1111/j.1365-2141.1990.tb07783.x

[27] D. Cella, M. J. Zagari, C. Vandorons, D. D. Gagnon, H. J. Hurtz and J. W. Nortier, "Epoetin Alfa Treatment Results in Clinically Significant Improvements in Quality of Life in Anemic Cancer Patients When Referenced to the General Population,” Journal of Clinical Oncology, Vol. 21, No. 2, 2003, pp. 366-373. doi:10.1200/JCO.2003.02.136

[28] M. Merlano, M. Benasso, G. M. Numico, M. Danova, A. Santelli, F. Ameli, F. Blengo, I. Ricci and M. Rosso, "5-Fluorouracil Dose Intensification and GranulocyteMacrophage Colony-Stimulating Factor in CisplatinBased Chemotherapy for Relapsed Squamous Cell Carcinoma of the Head and Neck: A Phase II Study," American Journal of Clinical Oncology, Vol. 21, No. 3, 1998, pp. 313-316. doi:10.1097/00000421-199806000-00024

[29] E. Azoulay, H. Attalah, A. Harf, B. Schlemmer and C. Delclaux, "Granulocyte Colony-Stimulating Factor or Neutrophil-Induced Pulmonary Toxicity: Myth or Reality?” Chest, Vol. 120, No. 5, 2001, pp. 1695-1701. doi:10.1378/chest.120.5.1695
[30] A. C. Hirbe, O. Uluçkan, E. A. Morgan, M. C. Eagleton, J. L. Prior, D. Piwnica-Worms, K. Trinkaus, A. Apicelli and K. Weilbaecher, "Granulocyte Colony-Stimulating Factor Enhances Bone Tumor Growth in Mice in an Osteoclast-Dependent Manner,” Blood, Vol. 109, No. 8, 2007, pp. 3424-3431. doi:10.1182/blood-2006-09-048686

[31] P. Fu, X. Jiang and M. O. Arcasoy, “Constitutively Active Erythropoietin Receptor Expression in Breast Cancer Cells Promotes Cellular Proliferation and Migration through a MAP-Kinase Dependent Pathway,” Biochemical and Biophysical Research Communications, Vol. 379, No. 3, 2009, pp. 696-701. doi:10.1016/j.bbrc.2008.12.146

[32] A. Mirmohammadsadegh, A. Marini, A. Gustrau, D. Delia, S. Nambiar, M. Hassan and U. R. Hengge, "Role of Erythropoietin Receptor Expression in Malignant Melanoma," Journal of Investigative Dermatology, Vol. 130, No. 1, 2010, pp. 201-210. doi:10.1038/jid.2009.162

[33] H. Lin, Y. H. She, B. R. Cassileth, F. Sirotnak and S. Cunningham-Rundles, "Maitake Beta-Glucan MD-Fraction Enhances Bone Marrow Colony Formation and Reduces Doxorubicin Toxicity in Vitro," International Immunopharmacology, Vol. 4, No. 1, 2004, pp. 91-99. doi:10.1016/j.intimp.2003.10.012

[34] H. Lin, S. W. Cheung, M. Nesin, B. R. Cassileth and S. Cunningham-Rundles, "Enhancement of Umbilical Cord Blood Cell Hematopoiesis by Maitake Beta-Glucan Is Mediated Granulocyte Colony-Stimulating Factor Production," Clinical and Vaccine Immunology, Vol. 14, No. 1, 2007, pp. 21-27. doi:10.1128/CVI.00284-06

[35] E. Suzuki, J. Sun, V. Kapoor, A. S. Jassar and S. M. Albelda, "Gemcitabine Has Significant Immunomodulatory Activity in Murine Tumor Models Independent of Its Cytotoxic Effects," Cancer Biology and Therapy, Vol. 6, No. 6, 2007, pp. 880-885. doi:10.4161/cbt.6.6.4090

[36] I. Matsuzaki, H. Suzuki, M. Kitamura, Y. Minamiya, H. Kawai and J. Ogawa, "Cisplatin Induces Fas Expression in Esophageal Cancer Cell Lines and Enhanced Cytotoxicity in Combination with LAK Cells," Oncology, Vol. 59, No. 4, 2000, pp. 336-343. doi:10.1159/000012192

[37] E. L. Spierings, H. Fujii, B. Sun and T. Walshe, “A Phase I Study of the Safety of the Nutritional Supplement, Active Hexose Correlated Compound, AHCC, in Healthy Volunteers," Journal of Nutritional Science and Vitaminology, Vol. 53, 2007, pp. 536-539. doi:10.3177/jnsv.53.536

[38] C. M. Mach, H. Fujii, K. Wakame and J. Smith, "Evaluation of Active Hexose Correlated Compound Hepatic Metabolism and Potential for Drug Interactions with Chemotherapy Agents," Journal of the Society for Integrative Oncology, Vol. 6, No. 3, 2008, pp. 105-109. 